\title{
UN MUNDO DE COLORES: FUERZA Y SIGNIFICADO DEL CROMATISMO EN LOS RELATOS DE VIAJES HISPANICOS A FINALES DE LA EDAD MEDIA
}

JuLia Roumier

AMERIBER, Universidad de Burdeos jroumier@u-bordeaux-montaigne.fr

\section{RESUMEN}

Se suele subrayar la parquedad de las menciones de colores presentes en los textos medievales. Incluso una especialista de los relatos de viajes medievales franceses llegó a calificarlos de «mundos en blanco y negro». Sin embargo los relatos de viajes hispánicos medievales suelen aludir al cromatismo de numerosos objetos. ¿En qué medida el arte descriptivo de los relatos de viajes descansa en las menciones cromáticas y qué funciones cumplen éstas? ¿Cómo proceden los autores para comunicar al lector las impresiones visuales? ¿qué sensaciones intentan compartir? Más allá del simbolismo, la materialidad de los colores parece un elemento clave que corresponde al interés propio de los Occidentales medievales por las riquezas de los territorios lejanos y los elementos lujosos que las más veces se caracterizaban por unos colores intensos y expresivos.

PALABRAs Claves: relatos de viajes, extranjero, colores, tintura, cartografía.

\section{RÉSUMÉ}

Il est couramment admis que la littérature médiévale n'abonde pas en adjectifs de couleurs. Au sujet des récits de voyages, Christiane Deluz a, par conséquent, parlé d'un monde en noir et blanc, affirmant que les couleurs en sont pratiquement absentes. La nature des descriptions que l'on trouve dans les récits de voyages médiévaux 
occidentaux tiendrait, selon elle, davantage du croquis ou du plan schématique que du tableau polychrome et détaillé. Il nous semble toutefois que cette affirmation doive être considérablement nuancée en ce qui concerne les récits de voyages médiévaux hispaniques dans lesquels ces précisions jouent un rôle particulièrement important. Au-delà du symbolisme, la matérialité des couleurs est un élément clé qui correspond à lintérêt des occidentaux du Moyen Âge pour les richesses des territoires lointains.

MoTS CLEFS: récits de voyages, étranger, couleurs, teintures, cartographie.

\section{INTRODUCCIÓN}

Los autores de los relatos de viajes conceden singular importancia a la descripción de las realia que componen la experiencia del extranjero que transmite el viajero. Esto abarca el conjunto de lo que vio el viajero, las personas a las que encontró, los monumentos, los animales... El efecto de realidad construido por estas descripciones corrobora la pretensión a la veracidad en que se fundamenta el interés didáctico de este tipo de obra. Estas descripciones pormenorizadas son particularmente importantes en los relatos basados en una experiencia real. A este propósito habló Francisco López Estrada de «realismo pictórico» en La Embajada a Tamorlán ${ }^{1}$. En efecto, el narrador de este famoso relato identifica con abundantes detalles la materialidad de lo experimentado, las dimensiones, las formas, los materiales y los colores, de gran importancia en las descripciones de los objetos de lujo.

Está sin embargo comúnmente admitido que dichas precisiones cromáticas no abundan en la literatura medieval. En cuanto a los relatos de viajes, Christiane Deluz afirmó la casi ausencia de los colores y habló de un mundo en blanco y negro². Según ella, las descripciones en los relatos de viajes medievales se asemejan más a un esbozo o un esquema que a un cuadro policromo y detallado.

Sin embargo, tenemos que matizar esta afirmación en cuanto a los relatos de viajes medievales hispánicos. Aquí trataremos de los relatos de viajes reales redactados en castellano como La Embajada a Tamorlán (1403) y Las Andanças e viajes de Pero Tafur (1454); también tendremos en cuenta los relatos ficticios como El libro del conosçimiento (redactado por un anónimo cerca de 1350) y las traducciones castellanas del Libro de las maravillas de Jean de Mandevilla y del Libro de Marco Polo. En estos textos aparecen numerosas indicaciones de colores y nos interesa poner de relieve en qué contexto aparecen, de qué forma se expresan y en qué manera se utilizan estas indicaciones. No tenemos que perder de vista la realidad material de los colores, propia del periodo medieval, en que no se entendían, producían, ni clasificaban los colores como en el periodo moderno. En efecto, en la Edad Media, se consideraban como más distintos un azul claro y un azul oscuro que un azul claro y un rojo claro. Los colores pálidos, descolorados, se consideraban como sub-colores y solo se valoraban los colores ricos y densos, los lla-

${ }^{1}$ López Estrada, Francisco (1943): Embajada a Tamorlán, estudio y edición de un manuscrito del siglo XIV, Madrid, CSIC, p. CCXXVI.

2 Deluz, Christiane (1988) «Un monde en noir et blanc? Les couleurs dans les récits de voyages et de pèlerinage», Les couleurs au Moyen Âge, Université de Provence, Sénéfiance, n. ${ }^{\circ} 24$, p. 57-69. 
mados «colores pleni». Estos colores caracterizan la ropa de las élites más ricas ya que necesitan la importación de productos costosos y la realización de complejos procesos de tintura. Así, por ejemplo, se podía teñir la ropa de un azul claro y descolorido con el pastel, una planta tintórea barata y abundante en Europa, mientras que el azul intenso necesitaba el uso del añil procedente de Oriente, caro y tildado de «tintura del Diablo». Ya vemos con esta distinción entre «colores pleni» y claros, la importancia en el tema de los colores de la jerarquía social y del Oriente proveedor de sustancias imprescindibles en el arte tintóreo.

\section{Materalidad Del CROMATismo}

De Oriente se importaban los pigmentos más estimados, considerados durante toda la Edad Media como parte de la categoría de las especias, con los aromáticos, el azúcar y el incienso ${ }^{3}$. Las materias usadas son así de suma importancia en el significado otorgado a los colores y en particular a estas sustancias que confieren su nombre a los colores. Así, ciertos autores de relatos de viajes manifiestan una gran atención para con las materias y mencionan con escrupuloso interés la concordancia entre el color y la naturaleza de un objeto. Encontramos tales indicaciones en múltiples ocasiones en La Embajada cuyo narrador presta peculiar importancia a la concordancia entre naturaleza y color del objeto: «que era cada uno de su color; un balax de buen color propio; cada uno de su color» ${ }^{4}$. El color está íntimamente ligado a la materialidad del objeto y la mera mención del material sirve para expresar la correspondencia con este color emblemático.

Así, en los relatos de viajes hispánicos encontramos frecuentes comparaciones que sirven para conferir vivacidad al cromatismo de las descripciones. El color blanco siempre es el objeto de comparaciones laudatorias que ensalzan su pureza y su brillo, al asemejar este color a la nieve o al cristal («piedra sal tan blanca como cristal» ${ }^{5}$ ). El color negro, por el contrario, está frecuentemente expresado por la comparación al carbón o a la pez ( «negros como la pez» ${ }^{6}$ ), de clara connotación peyorativa. Para el rojo, se alude en numerosas ocasiones a la expresiva comparación con la sangre en particular en las descripciones del Mar Rojo, como en El Libro del Conocimiento: «fallamos dos mares que era el agua d'ellas bermejas como sangre» (Rubio Tovar, op. cit., p. 385). También se encuentra la comparación con el fuego en el relato de Marco Polo: «bermejo como fuego» (Rubio Tovar, op. cit., p. 108). A menudo la indicación cromática no indica de que color se trata como si bastara con comparar con un elemento tópico para que el lector visualice el tinte; pero el elemento de comparación también sirve aquí para añadir dramatismo e impacto a la descripción de un lugar mítico de particular importancia en la cultura cristiana.

Le basta así al narrador con evocar la presencia material de los colores para provocar la impresión de su aspecto y la mera alusión a la multiplicidad de esos colores confiere

${ }^{3}$ Durel, Aline (2006): L'imaginaire des épices. Italie médiévale, Orient lointain (14e-15e siècles), Paris: L'Harmattan.

${ }^{4}$ Perez Priego, Miguel Ángel (2006): Viajes medievales, p. 78, 143, 151.

5 Rubio Tovar, Joaquín (2005): Viajes medievales, 1, Madrid, Fundación J. Antonio de Castro, p. 394.

${ }^{6}$ Rubio Tovar, Joaquín (2005): op. cit., p. 377, 380. 
bastante expresividad a la descripción. Así, en La Embajada, la expresión «muchos colores», repetida cuatro veces, y más aún, «muchas colores» repetida veinte veces, son un recurso sencillo y eficaz para aludir a los colores y suscitar su presencia en el espíritu del lector ${ }^{7}$. Este conjunto de ocurrencias designan creaciones humanas, ya sean de piedra como de materiales textiles. Estos objetos artísticos no tienen un color fijo, propio, esencial o natural como los objetos naturales, sino que se componen de varios colores cuya combinación se revela totalmente artificial y libre. No le importa al lector conocer con mas precisión cuales son esos colores y el narrador no se detiene para pormenorizarlos. Lo que cuenta, en cuanto a la expresividad de la descripción, es comunicar la impresión de conjunto provocada por la visión de este objeto artístico, provocar el mismo deslumbramiento en el lector que él inducido en el viajador por esta misma abundancia de colores difícilmente identificables. Pues la escritura sirve aquí antes que todo para restituir una impresión cromática, más que una descripción pormenorizada.

En la Embajada encontramos otro ejemplo de indicación cromática indefinida. Se refiere el narrador al polvo que cubre integralmente a los viajeros tras sus largas jornadas a caballo: «el polvo era tanto que las caras e las ropas todo era un color ${ }^{8}$. Lo que importa al autor en esta descripción no es propiamente dicho el color, que no se indica con precisión sino la continuidad de color, el aspecto monocromático de los viajeros totalmente cubiertos por una capa de polvo que confunde caras y ropa. Se trata aquí antes que todo de la ausencia de colores como elementos que permiten distinguir los distintos planos.

La precisión de las indicaciones de color revisten peculiar importancia en la descripción de las reliquias que tanto interesaban a los lectores de estos relatos; en efecto las indicaciones cromáticas satisfacen la curiosidad del lector y consolidan la afirmación de veracidad del relato ya que la precisión identifica el testimonio de primera mano. Así, por ejemplo, Pero Tafur, describe la saya sin costura de Jesucristo e indica como el tiempo marchitó su color: «la cual parecía que deviera ser morada e por longueça de tiempo estava como pardilla» ${ }^{9}$.

Las indicaciones cromáticas se multiplican claramente en los textos cuando los narradores llegan a Oriente, territorio de extensa definición y borrosos contornos. Antes que todo se trata del territorio definido por oposición al Occidente y cuyo linde está marcado por la ciudad de Constantinopla. La multiplicación de los elementos cromáticos en el tratamiento de los territorios orientales en los relatos de viajes corresponde a la práctica comprobada en los mapamundis medievales y, en particular, en los documentos coetáneos producidos en Mallorca. En las partes occidentales de dichos mapas, sólo se destacan los nombres de países y ciudades, con su símbolo arquitectónico, eventualmente unos escudos y unos ríos principales. En Europa y sus alrededores el cartógrafo dispone de tantas informaciones, precisas y documentadas que su redacción invade todo el espacio libre. La parte oriental del espacio cartográfico plantea el problema opuesto ya que la falta de información fiable incitaba al cartógrafo a que representara escenas

\footnotetext{
7 Se trata en particular de las descripciones de los mosáicos de Constantinopla; Pérez Priego, Miguel Ángel (2006): ob. cit., pp. 35, 36, 37, 43, 44, 46, 47, 50.

8 Pérez Priego, Miguel Ángel (2006): ob.cit., p. 146.

9 Pérez Priego, Miguel Ángel (2009): Andanças e viajes, Sevilla, Fundación José Manuel de Lara, p. 150.
} 
legendarias, ocasiones de variados colores. En el Atlas catalán de 1375, a estas escenas coloradas añadió el autor unas manchas de colores de aspecto decorativo, como en las múltiples islas de Extremo oriente. Dichas islas llenan el espacio marítimo y cada una está de un color totalmente injustificado. La alternancia cromática no parece aquí tener otra meta sino la estética, pero también contribuye a provocar una impresión de lujo y de belleza, un ensueño propio de estos territorios legendarios ${ }^{10}$.

\section{LOS TEJIDOS Y SUS COLORES}

Los tejidos de precio y sus colores vivos eran particularmente caros por su origen lejano. Por eso están tan íntimamente ligados a las representaciones de un Oriente de ensueño. Estos tejidos tan caros eran elementos suntuarios necesarios a la ostentación del poder. Por consecuencia, los autores demuestran un interés intenso por estos tejidos y sus colores obtenidos gracias a materiales tintóreos de origen lejano y asimilados a las especias. Describen los procedimientos empleados para teñir estos tejidos, los circuitos de comercio que tomaban y ésas eran informaciones esperadas por los lectores. En consecuencia, los relatos ficticios también transmitían estas informaciones como se observa en El Libro del Infante don Pedro de Portugal cuyo autor busca la precisión léxica en la descripción de los tejidos preciosos: «allí se labran los roçagantes y los paños de peso que son llamados tornasol y se labran los brocados mejores y más ricos del mundo» ${ }^{11}$. $\mathrm{El}$ autor busca relacionar una zona geográfica con la producción de un producto de precio, pero las descripciones quedan alusivas. El autor menciona el cromatismo sin dar más precisiones, sólo con el uso de un adjetivo que describe cómo el color cambia según la luz. En su relato Pero Tafur describe la ropa que, según él, le hubiera regalado el soldán: «la ropa que me dio el Soldán la cual era de acetimí verde e colorado, labrada de oro e forrada las muestras de armiño» ${ }^{12}$.

La descripción detalla el color vivo del tejido precioso: se trata de «acetimí» una palabra árabe «zaituni», es a decir raso. Es la única ocurrencia del color verde en todo el relato de Pero Tafur. El tinte verde vivo era uno de los más difíciles de obtener ya que se tenía que mezclar pigmentos azules y amarillos y que los únicos pigmentos verdes conocidos daban un resultado muy pálido y efímero. El concilio de Letrán de 1215 aun había promulgado una ley suntuaria que prohibía la ropa de color verde o rojo a los clérigos por ser ropa demasiado ostentadora ${ }^{13}$. Así, el color de esta ropa regalada a Pero Tafur revela su valor, y por lo mismo, da la medida del honor que representaba recibir tal regalo. Además, los tintes de esta ropa componen una armonía particularmente estimada en la Edad Media en la ropa de precio. Se preciaba mucho la combinación de rojo y verde, colores complementarios cuyo contraste choca mucho con la estética actual. La calidad y la riqueza de la ropa así ofrecida es un indicio mayor del estatuto del viajero

\footnotetext{
${ }^{10}$ Braga Corin (2003) «Mappemondes fantasmatiques. Principes non-empiriques de l'imaginaire cartographique», in: Caietele Echinox 5, pp. 32-72.

${ }^{11}$ En vez de «peso» indicado en esta edición, la secunda edición, la de 1547 reza «seda». Lasmarias, op. cit., p. 23.

12 Perez Priego, Miguel Ángel (2009): Pero Tafur: Andanças e viajes, Sevilla: fundación José Manuel Lara, p. 85.

${ }_{13}$ Pastoureau, Michel, Une histoire symbolique du Moyen Âge occidental, Paris: Seuil, 2004, p. 183.
} 
ante el Soldán y por esto se justifica plenamente el cromatismo de esta descripción que sirve antes que todo el proyecto de auto-promoción de Pero Tafur.

Juan de Mandeville ofrece del Catay la visión idealizada y tópica de una tierra de lujo en la que los tejidos más caros y refinados abundan y no valen más que las telas de lana en Occidente ${ }^{14}$. Aquí la expresión tópica del lujo oriental está basada en el elemento textil tan preciado. Mandeville se inspira en esto del relato de Odorico de Pordenone en el cual se puede leer a propósito del puerto de Hsinchou: «(çibdad) la qual de seda tiene mayor copia que en todo el mundo ser pueda, ca quando alli es la mayor carestia dela seda se pueden ende aver quarenta libras por menor presçio de ocho gruesos» ${ }^{15}$.

Este tipo de cita pone de realce como un franciscano en misión evangelizadora también presta atención a las informaciones de tipo comercial y detalla las variaciones de precio de los bienes de lujo, como para agradar a un lector generalmente interesado por estas cuestiones materiales.

Como lo hemos visto, los tejidos constituyen un indicador elocuente de la fascinación por el oriente mítico como fuente de riquezas y las indicaciones cromáticas precisas subrayan como comparten esta visión los autores de relatos de viajes tanto ficticios como reales.

\section{LOS COLORES COMO MARCAS DE PODER Y LUJO}

En cuanto a La Embajada, podemos comprobar que los colores surgen en este relato con la descripción de la basílica Santa Sofía ya que con ella aparece por vez primera la palabra «color» que se utiliza unas cuarenta veces en adelante ${ }^{16}$. Con la llegada de los embajadores a la Corte del gran Tamorlán, objetivo de su embajada, las menciones de color están a su máximo. Todas estas descripciones en colores permiten subrayar el poder y la riqueza del soberano mongol. Entre las veintiuna ocurrencias de «azul», dieciséis aparecen en esta descripción de la estancia de los embajadores en el reino de Tamorlán. Este color azul aparece íntimamente vinculado con esta región del mundo y esto se explica con las minas de azurita y de zafires allá explotadas ${ }^{17}$. Las trece ocurrencias de la palabra «azulejo» aparecen en la descripción de Samarcanda. Se trata de un elemento esencial para dar a conocer al lector lo propio de este espacio oriental marcado por el lujo de las decoraciones y de los elementos minerales utilizados.

Las descripciones por los embajadores castellanos de los palacios y de las tiendas en el campamiento de Tamerlán presentan una abundancia de detalles cromáticos. Esta acumulación enumerativa de materiales costosos comunica al lector el deslumbramiento experimentado por los embajadores que descubren la magnificencia del poder de Tamerlan, un poder político manifestado por estas riquezas coloradas ${ }^{18}$. La intensidad del

\footnotetext{
14 «Los panos de oro y de seda se fazen en aquella tierra donde tan barato valen aquellos como acá los panos de lana». Rubio Tovar, Joaquín (2005): op. cit., p. 305. Popeanga Chelaru, Eugenia, op. cit., p. 114.

15 Popeanga Chelaru, Eugenia (2007): Los viajes a Oriente de Odorico de Pordenone, Bucuresti: Cartea Universitară, p. 114.

${ }_{16}$ Perez Priego, Miguel Ángel (2006): op. cit., p. 35

17 Perez Priego, Miguel Ángel (2006): op. cit., p. 170; Se trata de la ciudad de Aq.

18 «Seda, esmeraldas, aljófar [...] dos mesas de oro [...] siete redomas de oro e las dos de ellas guarnidas de aljófar bien gruesso e de esmeraldas e turquesas», PEREZ PRIEGo (2006): ob. cit. p. 143.
} 
interés del narrador por estas riquezas se expresa por los numerosos adjetivos de colores utilizados. La mención del color de las piedras preciosas expresa su valor mercantil pero las más veces basta al narrador con mencionar el nombre de dicha piedra para evocar su color. Al contrario, el jaspe puede ser de varios colores y obliga a precisar la descripción.

También Pero Tafur describe con mucha precisión el color de los objetos preciosos. Por ejemplo, la indicación del color del caballo y de la ropa regalados al soldán por un vasallo suyo permite subrayar la majestad el soldán ${ }^{19}$. En su relato, tan interesado por el lujo, Pero Tafur sólo indica en una ocasión el color de un material bruto y desprovisto de valor mercantil. Se trata de lodo ( «Uno como lodo blanco» ${ }^{20}$.) pero no cualquier lodo sino el que remueven los que buscan oro en el río cerca de Basilea. Así el interés por este lodo está directamente vinculado con el proceso de prospección del mineral precioso y este lodo es ya el resultado de una primera filtración: ya contiene oro y por este mismo motivo interesa al autor.

Del mismo modo, las indicaciones de color revisten una función pragmática y didáctica en el relato de Juan de Mandeville cuando emprende una explicación pedagógica sobre como distinguir los buenos diamantes de los falsos. En estas paginas dedicadas a la temática del lapidario el autor le da al lector unos consejos prácticos que se apoyan en particular en la descripción de matices de color y de transparencia de las piedras. Dichos consejos semejantes a los de una guía para comerciantes abundan en el relato de Mandeville y frecuentemente se fundamentan en alguna fuente erudita. Para las páginas dedicadas a la descripción de las piedras preciosas y, particularmente de los diamantes, el autor se inspira en un lapidario ${ }^{21}$. Se multiplican los detalles precisos en cuanto al color, a la calidad de transparencia u opacidad, a los distintos grados de dureza, todos criterios para identificar las piedras auténticas. El narrador establece una jerarquía de los diamantes según su lugar de origen y las distinciones de color juegan un papel fundamental en dicha tipología.

\section{CUTIS Y JERARQUÍA HUMANA}

El cromatismo de las descripciones reviste una importancia mayor para los hombres extranjeros. En efecto los narradores califican, y aun clasifican, a los extranjeros en función del color de su tez, un elemento tanto realista como simbólico. Esta información aparece de forma sistemática, como si fuera indispensable para un buen conocimiento de la población descrita. Los narradores indican con precisión el color de la tez y del pelo y su matiz corresponde las más veces a la zonación climática. En efecto el mundo, según las teorías defendidas desde Microbio, se dividía en zonas paralelas al Ecuador. En la zona más nórdica se consideraba imposible la vida humana por el frío excesivo. La zona del Ecuador, llamada tórrida, está caracterizada por un calor excesivo que impide la presencia humana. Así la teoría climática de Macrobio en sus formas medievales fundamentaba la idea de la imposibilidad de acceder a este espacio prohibido, fuera del alcance

\footnotetext{
${ }_{19}$ Perez Priego, Miguel Ángel (2009): ob. cit., p. 84. «un cavallo de color morzillo (...) su ropa era de damasco blanco».

20 Perez Priego, Miguel Ángel (2009): ob. cit., p. 199.

${ }^{21}$ Rubio Tovar, Joaquín (2005): p. 256-257.
} 
de los viajeros occidentales ${ }^{22}$. Pierre d'Ailly en su Imago Mundi de 1410 desarrolla esta teoría climática del mundo y la consagra definitivamente ${ }^{23}$.

Las indicaciones de colores también permiten distinguir la religión, los origines étnicos o el rango social de algún personaje como es el caso en la descripción de la corte del Gran Khan en el relato de Odorico de Pordenone ${ }^{24}$. Juan de Mandevilla indica que los colores de las cofias permiten identificar las confesiones religiosas. También se conocían prácticas semejantes en la Península ibérica ${ }^{25}$.

La atención otorgada por estos narradores de relatos de viajes a los colores en la descripción del extranjero le confiere realismo, presencia visual y eficacia. Lejos de superfluas, estas indicaciones cromáticas transmiten un saber específico. El aspecto de testimonio es un elemento esencial de las estrategias de verosimilitud en las que estriban los textos. El relato de viaje es un texto personal y, si transmite un saber general sobre el extranjero, su autoridad le viene de la dimensión personal del testimonio realizado por un viajero que cuenta lo que personalmente presenció.

En los relatos de viajes medievales, el cutis negro se menciona sistemáticamente y aparece así como el señal patente de la alteridad radical del extranjero. Esto no carece de connotaciones ya que dicho color reviste una dimensión simbólica negativa en el Occidente cristiano: el Diablo, el pecado, la mancha tanto física como moral ${ }^{26}$. Las menciones de color de piel funcionan como un primer instrumento de deshumanización de los pueblos extranjeros. Si el viajero puede reconocer alguna calidad en dichos pueblos que pueden estar descritos, por ejemplo, como buenos guerreros o artesanos competentes, la formulación de la indicación del color de su cutis aparece como una contradicción con esta valorización, una negación y reafirma su alteridad radical ${ }^{27}$. El narrador de $L a$ Embajada a Tamorlán alude explícitamente a esta connotación diabólica del color negro cuando describe los nómadas «chacatays»: «Tan feos andavan del sol que parecían que del infierno salían e tanto parecían que parecían infinitos» ${ }^{28}$. El narrador asocia aquí el color cocido del cutis a las representaciones hiperbólicas del demonio que suele estar caracterizado por la abundancia de sus legiones.

La jerarquización de los colores humanos asociada a la teoría climática se fundamenta en la supuesta superioridad del cutis blanco, color original alterado por las intem-

${ }^{22}$ Braga, Corin (2004): Le paradis interdit au Moyen Âge: la quête manquée de l'Eden oriental, Paris: L'Harmattan, p. 10.

${ }^{23}$ Pierre d'Ailly, Ymago mundi, de Pierre d'Ailly, Cardinal de Cambrai et Chancelier de l'Université de Paris (1350-1420), Texte latin et traduction française des quatre traités cosmographiques de d'Ailly et des notes marginales de Christophe Colomb. Étude sur les sources de l'auteur, dir.: Edmond Buron, Librairie orientale et américaine, Maisonneuve frères, 1930, p. 197.

${ }^{24}$ «de diversas maneras seyendo vestidos e coronas en las cabeças suyas teniendo. Ca los primeros son vestidos de ropas de color verde, los segundos de color sanguineo e los terçeros de amarillo color son vestidos». Popeanga Chelaru, op. cit., p. 127. El relato de Guillaume de Rubrouck presenta descripciones similares.

${ }^{25}$ Ferrer I MaIllol, Maria Teresa (1987): Els sarrä̈ns de la corona catalano-aragonesa en el segle $X I V$, Barcelone, pp. 41-60.

${ }^{26}$ Devisse, Jean (1979): L'image du Noir dans l'art occidental. II. Des premiers siècles chrétiens aux Grandes découvertes, Paris: Bibliothèque des Arts. ROY, Bruno (1975) «En marge du monde connu: les races de monstres», in: Aspects de la marginalité au Moyen Âge, Guy H. Allard (dir.), Montreal.

${ }^{27}$ Jones, Ronald William (1971) «The Image of the Barbarian in Medieval Europe», in: Comparative Studies in Society and History, t. 13, Cambridge: Cambridge University Press, pp. 406-407.

${ }_{28}$ Perez Priego, Miguel Ángel (2006): op. cit., p. 123. 
peries y señal de perfección para un pensamiento etnocéntrico. Encontramos la misma idea en los escritos del naturalista y botánico Georges-Louis de Buffon según el cual la naturaleza, tan perfecta como tiene que ser, no pudo hacer a los hombres sino blancos. El cutis negro sería el producto hereditario de la exposición prolongada a un calor extremado $^{29}$.

El Libro del conosçimiento transcribe con fidelidad la teoría climática zonal y sus consecuencias sobre las poblaciones humanas: «non les faze ál la calentura salvo que los faze baços de color» ${ }^{30}$. El narrador describe así el cutis oscuro como una quemadura lo que contribuye a pintar estas regiones como un infierno hostil. Esto pinta indirectamente a sus habitantes como unos condenados cuyo aspecto refleja indudablemente el pecado que tuvieron que cometer previamente: «son gentes negras quemadas de la gran calentura del sol» ${ }^{31}$. Las variaciones del cutis están detalladamente justificadas por el narrador en un esfuerzo de racionalización de la descripción del mundo a través de una teoría apoyada en unas autoridades reconocidas y de clasificación de la multitud de formas humanas según unos principios más que favorables a los hombres occidentales. Al contrario los pueblos nórdicos se describen como muy pálidos, y se encuentra en particular en estos tópicos en la descripción de los Noruegos en El Libro del conosçimiento ${ }^{32}$.

Pero Tafur en su relato detalla los matices de la tez de los hombres a los que encuentra y relaciona sistemáticamente esta precisión con la zona climática en la que viven. Así la tez oscura aparece directamente vinculada con un calor excesivo que quema a los hombres y el narrador establece una gradación en la jerarquía humana que esboza: «la color de los ombres de la India Mayor es un poco más baços que nosotros e viniendo a la Etiopía, mucho más baços, e toda vía los negros ateçados que son al Mediodía, que dizen la zona quemada» ${ }^{33}$.

La gradación expresada establece un paralelo entre la zona geográfica y el cutis. Etiopía aparece como la zona más hostil a través del adjetivo «ateçado», tostado, ennegrecido por el fuego. En efecto, Etiopía es por antonomasia el país de los hombres negros expresión de la cual saca su propio nombre (según la etimología de «cara quemada $\left.{ }^{34}\right)$. Mandevilla afirma que sus habitantes son los más negros que se puedan encontrar: «los Nubianos son cristianos más son negros por la gran calor.[...] Etiopía donde son las gentes más negras que en otra parte» ${ }^{35}$.

Las poblaciones negras representan para los viajeros medievales de Occidente la alteridad más radical. Sin embargo estos viajeros comproban con asombro que pueden compartir una misma religión cristiana con los Etíopes. ¿Quién los convirtió? ¿Qué misionario se adentró hasta regiones tan hostiles? La creencia en la legendaria existencia de un reino cristiano de África negra se difundió potentemente en Europa, sobre todo

29 Duchet, Michèle (1995): Anthropologie et histoire au siècle des Lumières, Paris, Albin Michel: p. 269.

${ }^{30}$ Rubio Tovar, Joaquín (2005): p. 391.

31 Ibid., p. 386.

32 «son tierras yermas deshabitadas, pero que en algunos lugares habitan gentes e son omes viles e comen la carne e los pescados crudos e han los rotros luengos como canes pero que son blancos». RUBIO TovAR, Joaquín (2005): op. cit., p. 390.

33 Perez Priego, Miguel Ángel (2009): op. cit., p. 105.

${ }^{34}$ MedeIros, François de (1985): L'Occident et l'Afrique, 13e-15e siècle. Images et représentations, Paris: Khartala.

35 Rubio Tovar, Joaquín (2005): op. cit., p. 181 et 254. 
después de las embajadas enviadas por el soberano etíope a Venecia en 1402 y a la Corte catalano-aragonesa en $1427^{36}$. El reino del Preste Juan, situado en un primer tiempo en Extremo Oriente se trasladó a partir del signo XIV hacia Etiopía, cuyas poblaciones cristianas ofrecían un respaldo eficiente a la leyenda.

Se conocía su presencia en la región, pero se desconocía su identidad nestoriana así como la relativa vulnerabilidad de estas comunidades mucho menos potentes que lo hubieran deseado los cristianos de Occidente que soñaban con una alianza militar. Los relatos de viajes subrayan a menudo el contraste entre esta alteridad radical que representa el cutis negro de esta población y su identidad religiosa. Esta oposición viene expresada por frecuentes estructuras de concesión como por ejemplo en El Libro del conosçimiento:

«Ay siete montes que son poblados de gentes de los negros como la pez [...] es tierra muy poblada de cristianos de Nubia pero que son negros [...]. Preste Juan que es patriarca de Nubia e de Etiopía e señorea muy grandes tierras e muchas cibdades de cristianos pero que son negros como la pez e quémanse con fuego en señal de cruz» ${ }^{37}$.

Del mismo modo, los objetos negros se describen a menudo a través de la comparación hiperbólica con la pez, expresión lexicalizada de dimensión peyorativa. En efecto el negro es el color diabólico por excelencia y señala la maldición de la que sufren los que tienen la piel negra. Si tienen unas cualidades el narrador las presenta mediante estructuras de concesión: «e como quier que estas gentes son negros, pero son omes de buen entendimiento e de buen seso, e an saberes e ciencias» ${ }^{38}$. Dicha dificultad por parte de los viajeros o narradores para considerar a las poblaciones negras como capaces de una organización social y una cultura refinada también queda reflejada en las cartografía catalana de finales de la Edad Media. En estos documentos los personajes negros quedan fijados desnudos y en un tamaño muy inferior a los otros personajes, señal patente de inferioridad. Al contrario los soberanos, aunque pertenezcan a pueblos negros, están dibujado con una piel muy clara. En el Atlas Catalán, así se representan al emperador de Etiopia, el soldán de Babilonia, el rey de Nubia y «Rey d'Organa»; estos tres últimos están sin embargo representados como unos soberanos musulmanes, tocados con un turbante y sentados con las piernas cruzadas. El único Moussa Melli es en dicha carta un soberano de piel negra ${ }^{39}$. En el mapa de Villadeste, como en el Atlas Catalán, los soberanos africanos son blancos con la excepción de Mansa Moussa, rey de Guinea.

De manera similar, los hombres nórdicos se distinguen de los occidentales por el color de su piel, presentado y percibido como anormal y aun monstruoso. Su piel es muy blanca y su cara se caracteriza por unas facciones anormales que la mayoría de los narradores presentan como feas. En El Libro del conosçimiento, los habitantes de Noruega son cinocéfalos de piel muy blanca: «son tierras yermas deshabitadas, pero que en algunos lugares habitan gentes e son omes viles e comen la carne e los pescados crudos

${ }^{36}$ FALL, Yoro K. (1982): L'Afrique à la naissance de la cartographie moderne (14e-15e siècles: les cartes majorquines), Paris: Centre de recherches africaines, p. 190.

37 Rubio Tovar, Joaquín (2005): op. cit., p. 377 et 380.

38 Ibid., p. 380.

${ }^{39}$ Llompart Moragues, Gabriel, Pujades I Bataller, Ramón Josep, y Samso Moya, Julio (2005): El món i els dies: l'Atles Català, Barcelona: Enciclopedia Catalana, p. 124. 
e han los rotros luengos como canes pero que son blancos» ${ }^{40}$. El narrador de este relato ficticio también caracteriza a este pueblo por una alimentación de pescado crudo, clara señal de su dimensión monstruosa ya que los asimila a los ictiofagos, pueblo monstruoso heredado de las descripciones de Plinio, reputado vivir en Extremo-Oriente (Cf. El Atlas Catalán los representa como una pareja desnuda: VI, Sur-Sureste ${ }^{41}$ ).

En El Libro de las maravillas de Mandevilla, el color de la piel corresponde a esta misma zonación climática como por ejemplo con la piel particularmente pálida de los habitantes de Albania: «Albania donde las gentes son más blancas que nosotros» ${ }^{42}$; sin embargo a veces un pueblo específico representa una excepción en esta lógica de zonación. En el relato de Mandeville por ejemplo la ciudad de Abade en India está caracterizada por sus habitantes de tez muy blanca: «las gentes son ende muy blancas ${ }^{43}$. También se evoca a veces la existencia de unos pueblos de carnaciones más originales. Lo extraordinario de estos colores funciona como testimonio de la identidad monstruosa: «las gentes que moran alderredor de aquel río son todos de color verde y amarillo» ${ }^{44}$. Estos dos colores escapan de la mera gradación entre claro y oscuro para señalar con mas fuerza lo excepcional e inhumano de estos seres monstruosos.

\section{Colores de LA NATURALEZA}

El mar Rojo es un espacio marcado por el simbolismo que prevalece en su descripción. Los autores de relatos de viajes, aunque lo habrán visto, repiten la afirmación de este famoso color rojo impuesto por la tradición a pesar de la contradicción traída por la experiencia. Christiane Deluz demostró que en los relatos de peregrinación está muy arraigada esta afirmación: «Les pèlerins ne songent pas une seule fois à la dire bleue, voire violette, comme les Anciens» ${ }^{45}$. Las representaciones cartográficas siempre le dan al Mar Rojo este color desde la Antigüiedad y esto tuvo una influencia mayor en la mirada de los viajeros reales. El Atlas catalán intenta justificar este color en la leyenda que acompaña esta representación y, al hacerlo, señala que se trata de una convención gráfica sin ningún fundamento real: «Aquesta mar és appellade la mar Roga per on passaren los XII trips d'Issraell. E sepiats que l'aygua no és roga, mas lo fons és d'achela color» ${ }^{46}$. El Libro del conosçimiento confirma tener a un mapa de este tipo como fuente, ya que su narrador propone una explicación racional del color del mar Rojo según el modelo del Atlas, con una argumentación que se apoya en el color de los componentes minerales del fondo del mar: «este mare rubro dizen así porque el suelo d'el es almagre e tierra

\footnotetext{
${ }^{40}$ Rubio Tovar, Joaquín (2005): op. cit., p. 390.

${ }^{41}$ «Aquesta gent són salvatges que viven de peyx cruu e beven de la mar e van tots nuus». Llompart Moragues, G., Puchades i Bataller, R. J., Samso, Julio, op. cit., p. 175.

${ }^{42}$ Rubio Tovar, Joaquín (2005): op. cit., p. 246.

43 Ibid., p. 290.

44 Ibid., p. 257.

45 Deluz, Christiane (1988) «Un monde en noir et blanc? Les couleurs dans les récits de voyages et de pèlerinage», in: Les couleurs au Moyen Âge, 24, Aix-en-Provence: Université de Provence, Sénéfiance, p. 60.

${ }^{46}$ Llompart Moragues...(2005), op. cit., p. 143.
} 
bermeja e faze el agua ruvia $»^{47}$. Encontramos una explicación muy similar en el relato de Mandevilla ${ }^{48}$.

Se demuestra una misma atención al espectáculo de la naturaleza y una misma voluntad de sacar de éste una explicación racional en las descripciones de fenómenos volcánicos. Sobre este tema el narrador de La Embajada sólo ofrece unas anotaciones breves pero Mandevilla le dedica unas descripciones pormenorizadas. Una cueva en la ladera del Etna se hizo famosa por las llamas de colores que escupe. Los hombres de la isla suelen interpretar los distintos colores de estas llamas para establecer predicciones climáticas: «allí ay una gran caverna quemante que echa diversas flamas y colores, y por el mudamiento de aquellas flamas conoscen los de aquella tierra cuándo será el tiempo caro o barato, o frío o caliente, o húmido o seco, y en todas las maneras cuando el tiempo se mиda» ${ }^{49}$. En este ejemplo el relato de viaje transmite la descripciones de prácticas populares locales que delatan una gran atención a los colores de la naturaleza. Los hombres interpretan sus variaciones para sacar de éstas un saber empírico. Los colores de las llamas y del humo constituyen unos signos que los hombres intentan organizar en sistema para que, de ésta lógica salga un pronóstico. Así se sale de lo maravilloso que suscita el asombro del narrador para llevar al lector al terreno de la ciencia empírica emergente que permite otorgar un sentido a estos colores aparentemente arbitrarios.

Las descripciones de paisajes naturales también son la ocasión textual para que el narrador exprese su gusto por los colores, más presentes en La Embajada que en otros relatos de viajes. Las indicaciones cromáticas también delatan la curiosidad artística de un autor como en el relato de Pero Tafur que las utiliza con abundancia en las descripciones de realizaciones arquitectónicas. Así por ejemplo su descripción del Templo de Salomón se caracteriza por una intensa emoción estética y un interés marcado por los colores: «Vi todo el templo el cual es una nave sola toda de oro musáico labrada e el suelo e paredes de muy fermosas losas blancas e tantas lámparas colgadas que parece que se junta unas con otras [...]. Ciertamente dizen que este fue, cuando Salomón lo fizo, la mejor obra que uvo en el mundo [...] $\gg^{50}$.

\section{LOS COLORES COMO SIGNOS DE INVERSIÓN}

Como lo subraya el narrador de La Embajada, normas y juicios de valor difieren en el extranjero respecto a España, e incluso aparecen contrarios. En efecto, el extranjero aparece a menudo pintado como un espejo inverso de la sociedad cristiana occidental de que provienen los viajeros. En la corte de Tamerlán, los embajadores castellanos descubren con sorpresa que las jerarquías estéticas están totalmente al revés. Los cabellos negros están de moda y las mujeres se tiñen para corresponder a este ideal estético: «Ellos se pagan mucho de cabellos negros antes que de otra color e tínenlos por los fazer negros $»^{51}$.

\footnotetext{
${ }^{47}$ Rubio Tovar, Joaquín (2005): op. cit., p. 383.

48 «aquesta mar por cierto no es vermeja más que otra empero en algunos lugares ay algunas rocas coloradas por aquesto lo llaman la mar roja». Ibid., p. 189.

49 Rubio Tovar, Joaquín (2005): Ibid., p. 187.

50 Perez Priego, Miguel Ángel (2009): ob. cit.., p. 69.

51 Perez Priego, Miguel Ángel (2006): op. cit., p. 161
} 
Se puede encontrar una referencia similar en el relato redactado por Poggio Bracciolini $^{52}$. Marco Polo profundiza aún más este tema de la inversión de los valores. Según él, los hombres no nacen negros sino que se ennegrecen voluntariamente por amor a este color. En efecto, el color negro sería para ellos el más digno de loa y admiración, el color más bello y el color de los dioses. El narrador pone de realce la inversión que representa esta perspectiva con respeto al sistema occidental cristiano en el que los diablos son negros, negros como el pecado, la suciedad y el infierno ${ }^{53}$.

\section{CONCLUSIÓN}

Los colores son elementos claves en la construcción de la representación del mundo por los relatos de viajes. Muy lejos de ser en blanco y negro, el mundo descrito por los viajeros medievales hispánicos presenta una abundancia de colores que le confieren vivacidad, materialismo y realismo. Estas indicaciones cromáticas sirven para atraer la atención de los lectores y realzar los elementos de peculiar interés. Están generalmente vinculadas a un material que les confieren peso, espesor concreto. Las comparaciones tópicas cumplen la misma función retórica y permiten una más fácil visualización del color mientras aclaran su dimensión simbólica como la pez o la nieve. Con la distinción entre «colores pleni» y claros, con la descripción pormenorizada de los tejidos y otros elementos de lujo y con la gradación de los colores humanos, se revelan la importancia de los colores en la manifestación de la jerarquía social y la representación del Oriente proveedor de sustancias imprescindibles en el arte tintóreo.

52 «mayormente cabellos negros que es color entre ellos más estimado». RUBIo Tovar, Joaquín (2005): op. cit., p. 135-136.

53 «Los hombres desta tierra son todos negros no porque nacen negro mas para que se tornen bien negros se untan con azeite de ajonjolí, porque cuanto son más negros, tanto se tienen por más hermoso; [...] hazen pintar sus ídolos negros y los demonios pintan blancos». Ibid., p. 112. 
